\title{
METODOLOGIA PARA OBTENÇÃO DO HIDROGRAMA DE ESCOAMENTO SUPERFICIAL EM ENCOSTAS E CANAIS. PARTE II: MODELO COMPUTACIONAL E ANÁLISE DE SENSIBILIDADE
}

\author{
JOSÉ M. A. SILVA ${ }^{1}$, FERNANDO F. PRUSKI ${ }^{2}$, DEMETRIUS D. SILVA ${ }^{3}$, \\ ROBERTO A. CECÍLIO ${ }^{4}$
}

\begin{abstract}
RESUMO: Estimativas de vazão máxima de escoamento superficial são necessárias para o projeto de obras hidráulicas em bacias urbanas e rurais. A dificuldade em aplicar os procedimentos disponíveis para calcular a variação do escoamento superficial com o tempo e de seu valor máximo deve-se à inexatidão dos métodos usados para esse objetivo e à variabilidade nos resultados que podem ser obtidos por profissionais que usem o mesmo procedimento. Dessa forma, a investigação de um método que produza estimativas confiáveis da vazão máxima e do hidrograma de escoamento superficial é de grande interesse. Neste trabalho, desenvolveu-se e avaliou-se a sensibilidade de um software (HIDROGRAMA 2.1) que permite a obtenção do hidrograma de escoamento superficial, da vazão máxima e seu tempo de ocorrência, da altura e da velocidade máximas do escoamento, do volume e da lâmina de escoamento superficial em encosta e em canais. O modelo apresentou grande sensibilidade ao período de retorno, à taxa de infiltração estável e ao comprimento da encosta e do canal.
\end{abstract}

PALAVRAS-CHAVE: modelagem hidrológica, conservação de água e solo.

\section{METHODOLOGY FOR OBTENTION OF SUPERFICIAL FLOW HYDROGRAPH IN HILLSIDES AND CANALS. PART II: COMPUTER MODEL AND SENSITIVITY ANALYSIS}

\begin{abstract}
Estimative of maximum runoff flow rates are essential for the projects of hydraulic urban and rural basins. The difficulty in applying the available procedures to estimate the temporary variation of the flow rate and its maximum value is due to the inaccuracy of some methods that are usually used and to the big variability of results that can be obtained by different professionals that use the same procedures. Therefore, research of a method that produces trustworthy assessment of peak-flow rates and hydrographs is of great interest. This paper describes the development and sensitivity analysis of a software (HIDROGRAMA 2.1) that allows obtaining surface runoff hydrograph, peak flow rate and its time of occurrence, runoff maximum height, runoff velocity and runoff volume. The model presented great sensibility to precipitation return period, infiltration rate after long time of wetting and hillside and channel length.
\end{abstract}

KEYWORDS: hydrologic modeling; soil and water conservation.

\section{INTRODUÇÃO}

A estimativa de vazões máximas de escoamento superficial é freqüentemente necessária tanto em bacias hidrográficas com ocupação agrícola quanto naquelas com ocupação urbana (BONTA \& RAO, 1992). O dimensionamento de drenos, barragens e obras de proteção contra cheias e erosão hídrica requer o estudo das precipitações intensas para a obtenção da altura da chuva de projeto, com a qual é definida a vazão a ser utilizada. No projeto de estruturas de controle de erosão e inundação, são necessárias, também, informações sobre o escoamento superficial. Quando o objetivo é reter ou armazenar toda a água, o conhecimento do volume escoado é suficiente. Por outro lado, se há necessidade da condução do excesso de água para fora da área de interesse, a determinação da vazão de escoamento superficial torna-se mais importante, particularmente a vazão correspondente a um determinado período de retorno (SCHWAB et al., 1966).

\footnotetext{
${ }^{1}$ Engo Civil, DS Engenharia Agrícola, DEA/UFV, Viçosa - MG, Fone (OXX31) 3899-1912, jmarcio@ gprh.ufv.br

${ }^{2}$ Eng ${ }^{0}$ Agrícola, Prof. Titular, DEA/UFV, Bolsista do CNPq, ffpruski@ ufv.br

${ }^{3}$ Eng $^{\text {o }}$ Agrônomo, Prof. Adjunto, DEA/UFV, Bolsista do CNPq, david@ufv.br

${ }^{4}$ Eng $^{\circ}$ Agrícola, DS Engenharia Agrícola, DEA/UFV, rcecilio@ vicosa.ufv.br

Recebido pelo Conselho Editorial em: 5-10-2005
}

Aprovado pelo Conselho Editorial em: 5-9-2006 
Do volume total precipitado, uma parte é interceptada pela vegetação, enquanto o restante atinge a superfície do solo. $\mathrm{O}$ empoçamento da água, nas depressões existentes na superfície do solo, começa a ocorrer somente quando a intensidade de precipitação excede a taxa de infiltração, ou quando a capacidade de armazenamento de água no solo for ultrapassada. Esgotada a capacidade de retenção superficial, a água começará a escoar. Associado ao escoamento superficial, ocorre o transporte de partículas do solo. Portanto, se a intensidade da precipitação, excluindo a interceptação e as perdas por evaporação, for menor que a taxa de infiltração, toda a água precipitada infiltrará no solo; inversamente, quando a intensidade da precipitação for maior do que a taxa de infiltração, uma seqüência de eventos ocorrerá, produzindo escoamento superficial (GRAY, 1973).

De acordo com McMILLAN \& BURGY (1960), a interceptação pode ser definida como o processo de retenção da precipitação pela vegetação. A água da precipitação retida em poças, diques e outras depressões da superfície do solo é chamada de armazenamento superficial. Devido à dificuldade em quantificar a interceptação pela cobertura vegetal e o armazenamento superficial, o Soil Conservation Service (SCS) propôs, por intermédio da metodologia caracterizada como Curve Number (Número da Curva), um termo utilizado para estimar esses componentes, o qual é designado abstrações iniciais, caracterizando toda a precipitação que ocorre antes do início do escoamento superficial (SIMANTON et al., 1996).

Segundo BONTA \& RAO (1992), a investigação de um método que produza estimativas confiáveis de vazão máxima de escoamento superficial, torna-se fundamental para que se possa fazer um correto dimensionamento de obras hidráulicas.

SILVA et al. (2006) desenvolveram um método, denominado HIDROGRAMA, capaz de gerar hidrogramas de escoamento superficial, utilizando o modelo de ondas cinemáticas. Entretanto, a aplicação desse modelo exige a utilização de sistemas computacionais. No presente trabalho, teve-se o objetivo de desenvolver e promover a análise de sensibilidade de um software que, utilizando o método HIDROGRAMA, possibilite a obtenção do hidrograma de escoamento superficial, da vazão máxima e seu tempo de ocorrência, da altura e velocidade máximas do escoamento, do volume e da lâmina de escoamento superficial decorrente da precipitação para qualquer pixel ao longo de uma encosta (com declividade num único sentido) e para seções transversais do canal de terraços ou drenos de superfície, uma vez que as informações relativas à área tenham sido fornecidas.

\section{MATERIAL E MÉTODOS}

\section{Desenvolvimento do software}

Desenvolveu-se o software denominado HIDROGRAMA 2.1, em ambiente de programação Borland Delphi 5.0, que permite, uma vez definidas as condições típicas da área de interesse, a aplicação da metodologia desenvolvida por SILVA et al. (2006), a qual possibilita obter o hidrograma de escoamento superficial decorrente da precipitação para qualquer pixel ao longo de uma encosta (com declividade num único sentido) e no canal do terraço ou dreno natural, pelo qual é feita a drenagem do escoamento superficial que ocorre na área considerada.

O programa computacional foi projetado para ser executado em plataforma "Windows 98" ou superior, possuindo interface de fácil utilização e auto-explicativa. Conta com sistema de ajuda que disponibiliza informações pertinentes aos dados de entrada e saída, bem como com informações para auxiliar o entendimento da parte técnica para a solução de dúvidas referentes à utilização do software.

\section{Análise de sensibilidade}

Os resultados dos estudos de sensibilidade de modelos fornecem informações sobre o comportamento do modelo e, também, sobre falhas na metodologia utilizada no desenvolvimento do modelo e na sua aplicabilidade em diferentes cenários e escalas (GOWDA et al., 1999). A 
análise de sensibilidade constituiu em quantificar o efeito da variação de cada uma das principais variáveis de entrada do modelo de SILVA et al. (2006) nos valores de vazão máxima $\left(Q_{\text {máx }}\right)$ e lâmina de escoamento superficial (LES) calculados, mantendo-se fixas as demais variáveis. Esse procedimento visou a identificar quais as variáveis de entrada que necessitam de maior rigor em sua determinação.

Para a realização da análise, admitiu-se como condição-padrão uma área com as seguintes características: encosta regular com declividade $\left(\mathrm{I}_{\text {encosta }}\right)$ de $20 \%$, comprimento ( $\left.\mathrm{L}_{\text {encosta }}\right)$ de $60 \mathrm{~m}$, terminando em um canal com extensão $\left(\mathrm{L}_{\text {canal }}\right)$ de $300 \mathrm{~m}$. A taxa de infiltração estável $\left(\mathrm{T}_{\mathrm{ie}}\right)$ considerada para a encosta foi de $20 \mathrm{~mm} \mathrm{~h}^{-1}$, e o coeficiente de rugosidade $\left(\mathrm{n}_{\text {encosta }}\right)$ foi de 0,040 . Considerou-se um canal com seção transversal trapezoidal, declividade $\left(\mathrm{I}_{\text {canal }}\right)$ de 1,0\% e coeficiente de rugosidade $\left(\mathrm{n}_{\text {canal }}\right)$ igual a 0,020 . Tomou-se o período de retorno $(\mathrm{T})$ da precipitação como sendo igual a 10 anos, sendo utilizada a equação de intensidade-duração-freqüência determinada por PINTO (1995) para a localidade de Viçosa - MG.

\section{RESULTADOS E DISCUSSÃO}

\section{Software desenvolvido}

O software HIDROGRAMA 2.1 foi estruturado na forma dos seguintes módulos:

\section{a) Módulo Principal}

Gerencia o funcionamento do software, a inicialização e a finalização, a visualização de formulários, a leitura e a gravação de arquivos de dados.

\section{b) Módulo Entrada de Dados}

Tem por finalidade fornecer os dados necessários à obtenção do hidrograma de escoamento superficial: parâmetros da equação de intensidade-duração-freqüiência da precipitação, características do canal (declividade, comprimento, rugosidade e inclinação da parede de montante), características da encosta (rugosidade, comprimento, declividade, taxa de infiltração estável da água no solo e cobertura vegetal, para a determinação das abstrações iniciais). A tela referente ao módulo Entrada de Dados é mostrada na Figura 1.

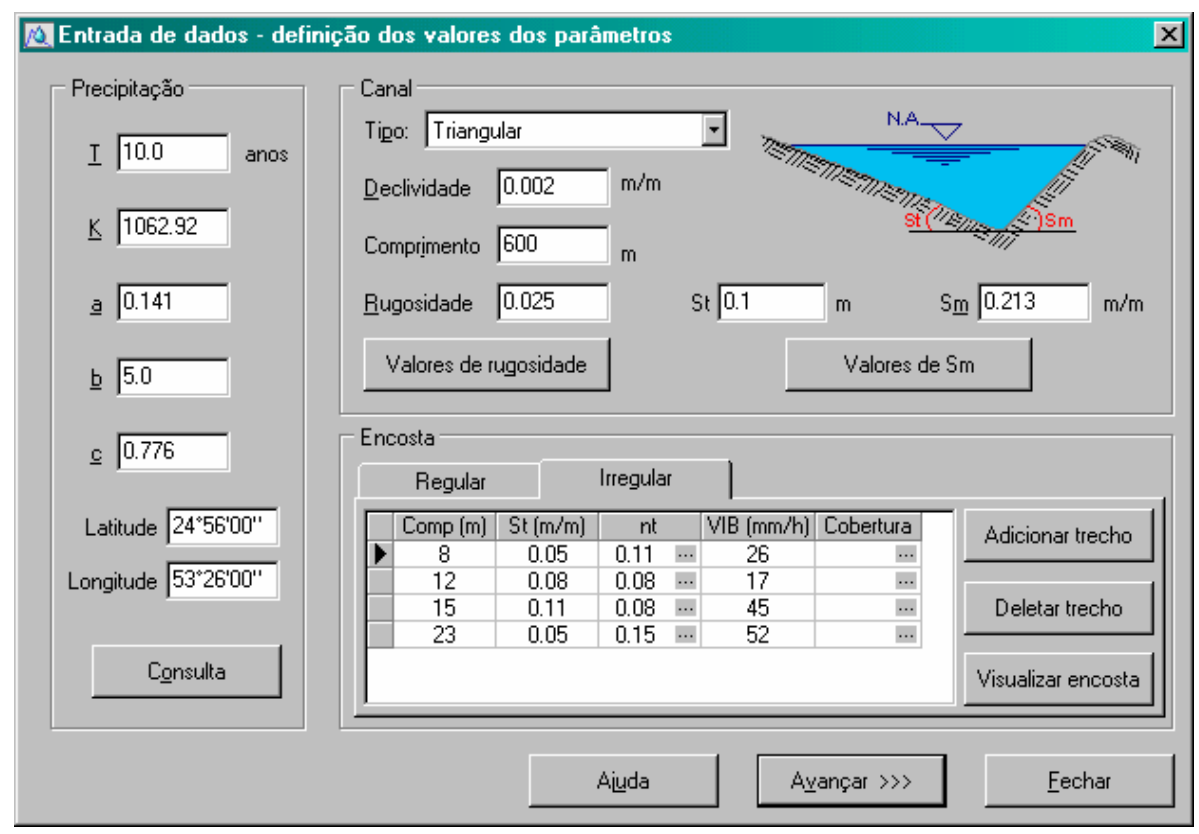

FIGURA 1. Tela referente ao módulo Entrada de Dados.

O usuário pode dividir a encosta em vários trechos, caso ocorra a mudança de alguma variável, ou um único trecho. A primeira opção é dita Encosta Irregular, sendo a segunda Encosta Regular. Na Figura 2, apresenta-se a visualização do perfil da encosta considerando Encosta Irregular, estando essa dividida em quatro trechos. 


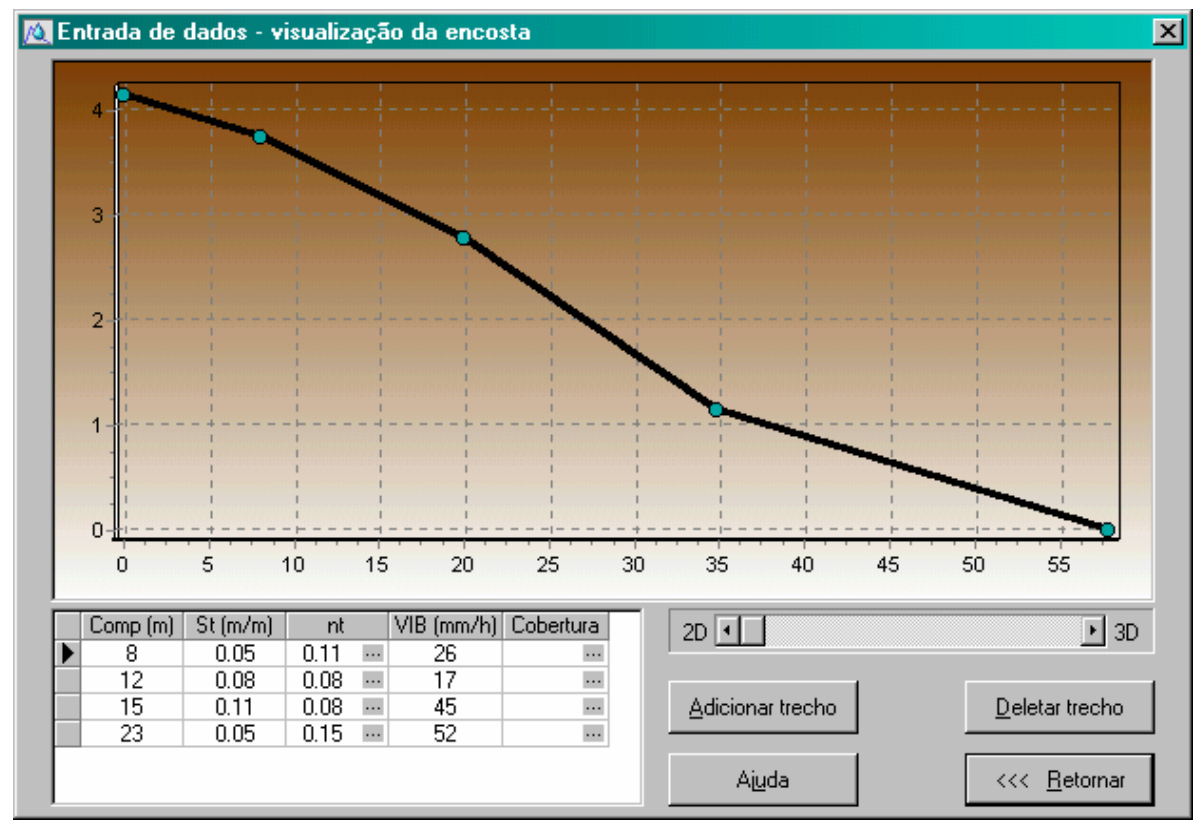

FIGURA 2. Tela relativa à visualização do perfil de uma encosta irregular, estando essa dividida em quatro trechos.

\section{Precipitação}

Permite a obtenção dos parâmetros K, a, b, c da equação de intensidade-duração-frequiência da precipitação. As formas para sua obtenção são: a partir de um banco de dados em que são apresentadas ao usuário as diversas localidades dos Estados brasileiros onde os parâmetros são conhecidos e a partir de mapas que foram obtidos para o Espírito Santo, Minas Gerais, Paraná, Rio de Janeiro e São Paulo com o uso de um interpolador. Nesse caso, cabe ao usuário fornecer a latitude e a longitude da localidade de interesse ou identificá-la a partir de um banco de dados em que constam as latitudes e longitudes de sedes de municípios, vilas e distritos. O usuário pode também fornecer os parâmetros para a localidade em que a equação de chuvas intensas não está disponível. Na Figura 3, visualiza-se a consulta ao banco de dados para a determinação dos parâmetros da equação IDF.

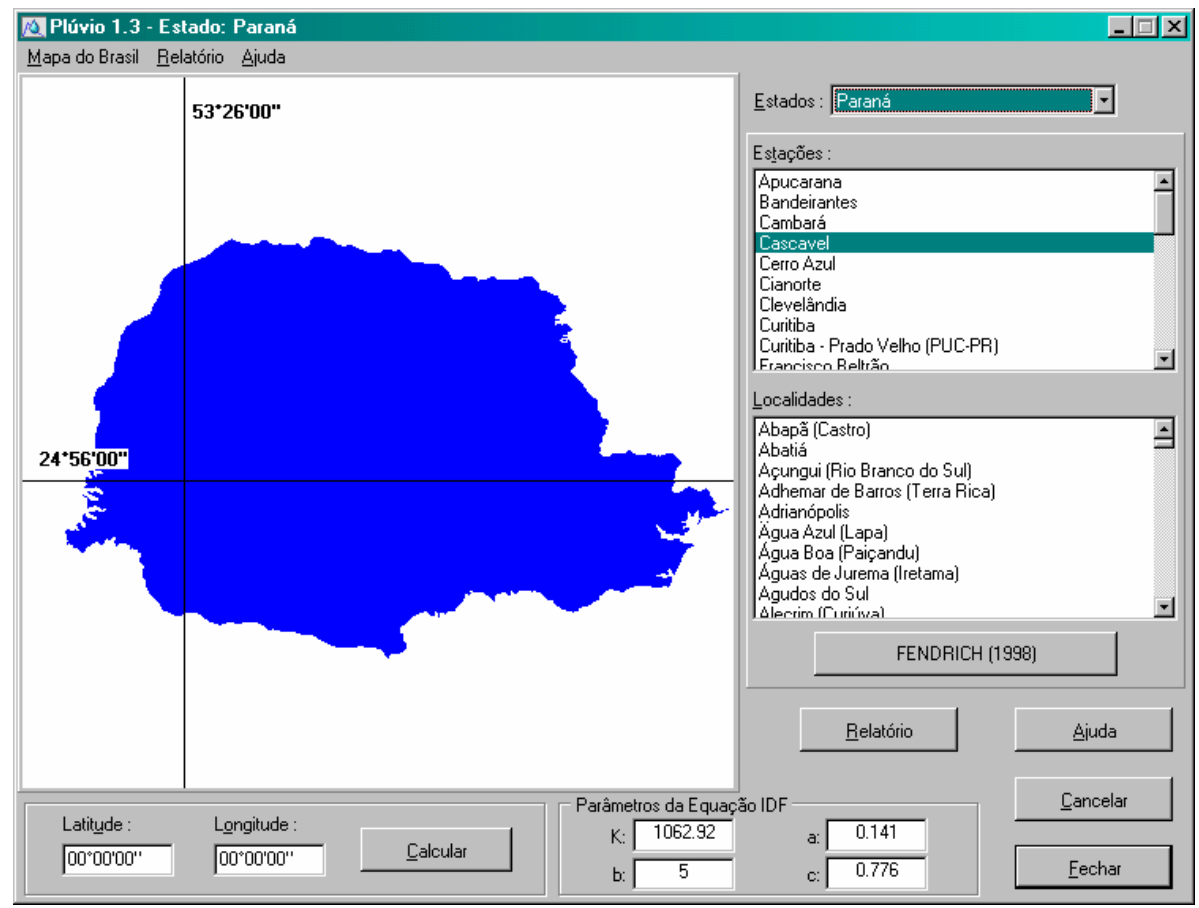

FIGURA 3. Tela relativa à obtenção dos parâmetros da equação de intensidade-duração-freqüência da precipitação. 


\section{Rugosidade do terreno}

Permite ao usuário consultar um banco de dados que contém informações sobre o valor de rugosidade para diferentes condições de uso e manejo do solo. Os valores que constam do banco de dados são aqueles obtidos de BEASLEY \& HUGGINS (1981).

\section{Caracterísicas da seção transversal dos canais}

No HIDROGRAMA 2.1, o usuário pode optar por canais com dois tipos de seção transversal: trapezoidal ou triangular. Para canais triangulares, o usuário pode consultar um banco de dados em que os valores de declividade da parede de montante do canal (Sm) estão associados ao sistema construtivo do canal. Esses valores de Sm foram obtidos de CODASP (1994). Para canais de seção transversal trapezoidal, o software disponibiliza um banco de dados obtido de BERNARDO et al. (2005), com valores do talude do canal (Z).

\section{Rugosidade do canal}

Permite ao usuário consultar um banco de dados que contém informações sobre o valor de rugosidade para diferentes tipos e condições de canais. Os valores apresentados no banco de dados são os obtidos de CHOW (1986).

\section{Cobertura vegetal}

Permite a determinação das abstrações iniciais pelo Método do Número da Curva do Soil Conservation Service (USDA-SCS, 1985). Para tanto, o usuário deve definir o tipo de uso e manejo do solo e a condição hidrológica em que se encontra a área considerada.

\section{c) Módulo Hidrograma}

Esse módulo emprega a metodologia desenvolvida por SILVA et al. (2006) para a obtenção do hidrograma de escoamento superficial. Uma vez obtidos os dados de vazão e tempo, os valores dessas variáveis são plotados em um gráfico.

Após fornecer todas as variáveis necessárias à obtenção do hidrograma de escoamento superficial, o usuário pode escolher entre obter o hidrograma na encosta ou no canal de drenagem (Figura 4).

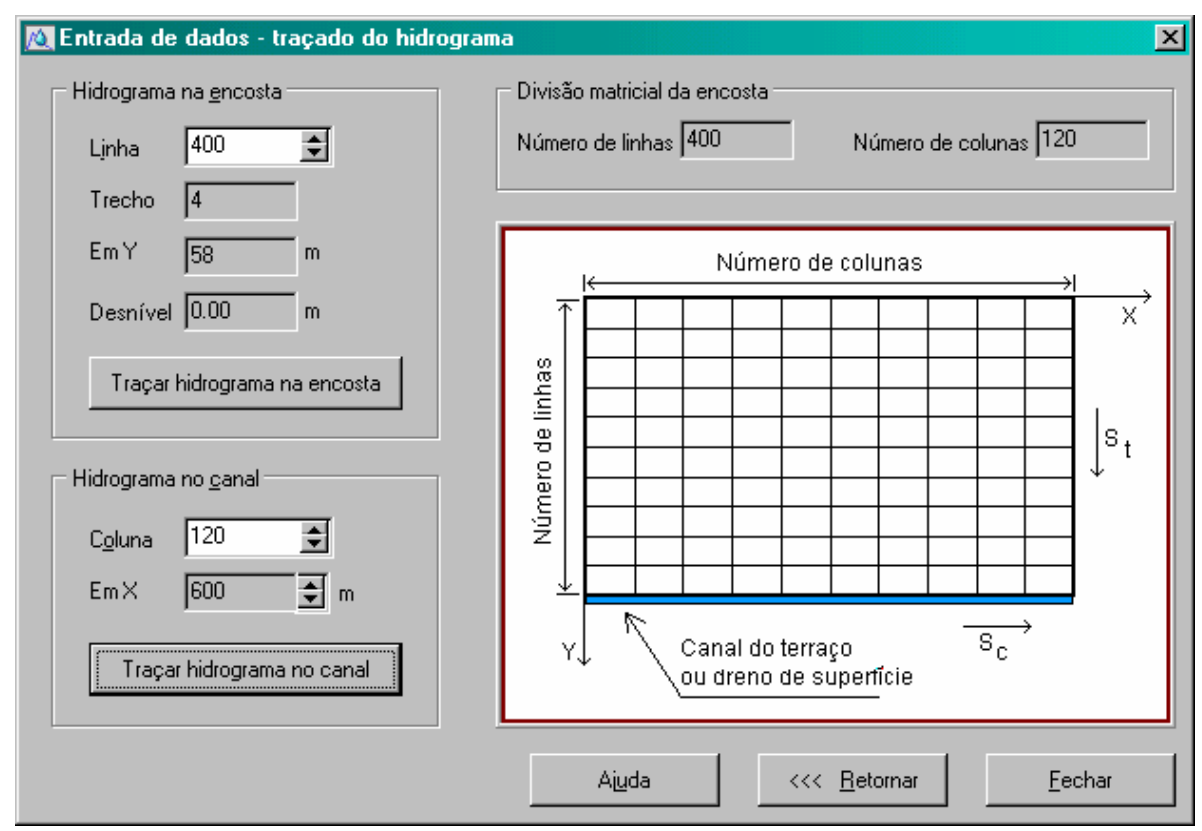

FIGURA 4. Tela relativa ao módulo Hidrograma, o qual permite traçar o hidrograma na encosta ou no canal.

Na Figura 5, apresenta-se uma visão mais detalhada do hidrograma de escoamento superficial obtido, considerando condições de escoamento no canal e as opções disponíveis. Essas opções permitem: 
- Imprimir o hidrograma;

- Salvar os dados numéricos do hidrograma em um arquivo-texto;

- Salvar o hidrograma como um "bitmap" ou copiá-lo para a área de transferência do Windows;

- Gerar um relatório, e

- Visualizar os valores numéricos.

Cópias do software podem ser obtidas gratuitamente no site www.ufv.br/dea/gprh, seção Softwares - Hidrograma.

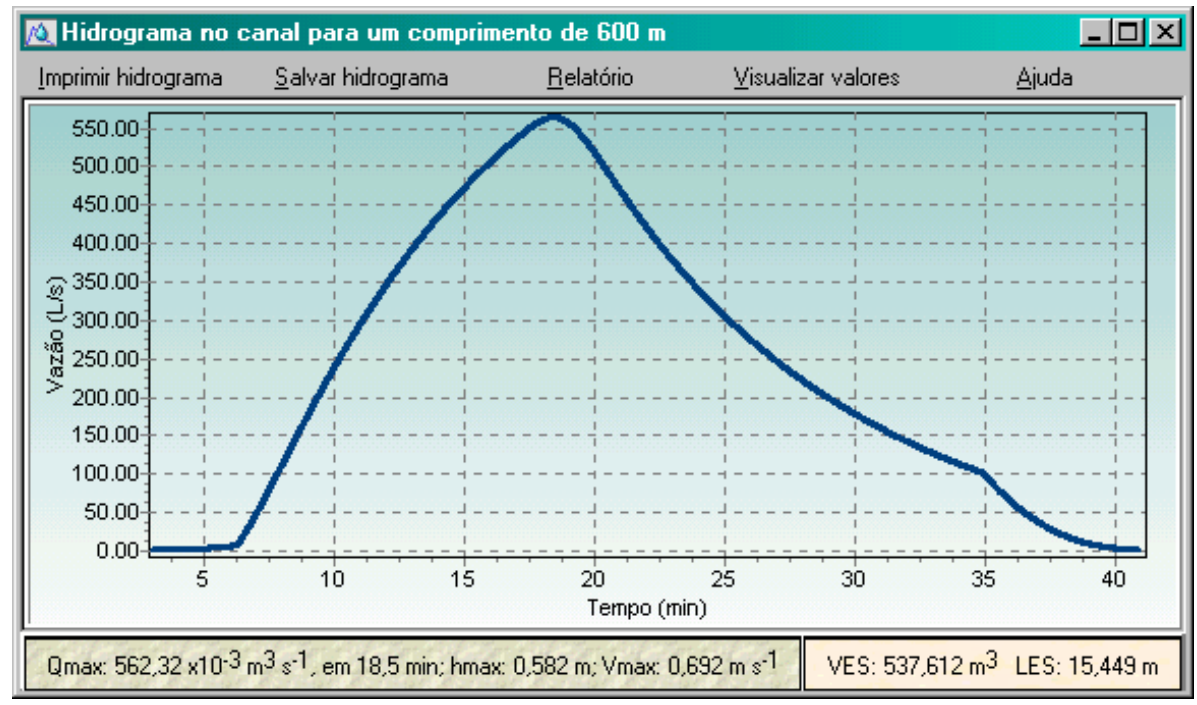

FIGURA 5. Tela relativa ao hidrograma de escoamento superficial, considerando condições de escoamento no canal, visualizando-se o valor da vazão máxima (Qmáx) e seu tempo de ocorrência, a altura (hmax) e a velocidade (Vmax) máximas de escoamento e o volume (VES) e a lâmina de escoamento superficial (LES).

\section{Análise de sensibilidade}

Na Figura 6, apresentam-se as variações do valor de $\mathrm{Q}_{\text {máx }}$ em resposta às mudanças relativas dos valores das variáveis de entrada $\mathrm{T}, \mathrm{T}_{\mathrm{ie}}, \mathrm{I}_{\text {canal }}, \mathrm{L}_{\text {canal }}, \mathrm{n}_{\text {canal }}, \mathrm{I}_{\text {encosta }}$, $\mathrm{L}_{\text {encosta }}$ e $\mathrm{n}_{\text {encosta. }}$ Observa-se alta sensibilidade à variação, tanto do comprimento da encosta $\left(\mathrm{L}_{\text {encosta }}\right)$ quanto ao comprimento do canal ( $\mathrm{L}_{\text {canal }}$ ), e o incremento desses causa incremento em $\mathrm{Q}_{\text {máx. }}$ Isso pode ser explicado pelo fato de os incrementos em $\mathrm{L}_{\text {canal }}$ e $\mathrm{L}_{\text {encosta }}$ ocasionarem aumento da área analisada, o que acaba por gerar maior volume e, conseqüentemente, concentração do escoamento superficial, acarretando maior vazão. Percebe-se que o crescimento da $Q_{\operatorname{máx}}$ não apresenta comportamento linear com o


necessário para a concentração do escoamento superficial provindo de toda a área.

Ainda em relação à Figura 6 , alta sensibilidade está associada às variáveis $\mathrm{T}$ e $\mathrm{T}_{\mathrm{ie}}$, e à medida que o período de retorno diminui, ocorre maior sensibilidade a essa variável. $\mathrm{O}$ aumento de $\mathrm{T}$ ocasiona crescimento de $\mathrm{Q}_{\text {máx }}$, uma vez que, associado ao seu aumento, também ocorre aumento da intensidade da chuva de projeto, causando maior escoamento superficial. $\mathrm{O}$ incremento de $\mathrm{T}_{\text {ie }}$ causa redução no valor de $\mathrm{Q}_{\text {máx }}$ pelo fato de haver maior infiltração da água no solo.

Evidenciou-se pouca sensibilidade à variação dos coeficientes de rugosidade e das declividades, tanto do canal, quanto da encosta, sendo a sensibilidade à variação das rugosidades ligeiramente superior. As declividades interferem na $\mathrm{Q}_{\text {máx }}$ apenas em termos de redução do tempo de concentração do escoamento superficial. 
A análise geral dos resultados apresentados na Figura 6 mostra que as variáveis $\mathrm{L}_{\text {canal }}, \mathrm{L}_{\text {encosta, }}$, $\mathrm{T}$ e $\mathrm{T}_{\mathrm{ie}}$ devem ser determinadas de forma mais rigorosa quando do projeto de obras hidráulicas destinadas à condução do escoamento superficial.

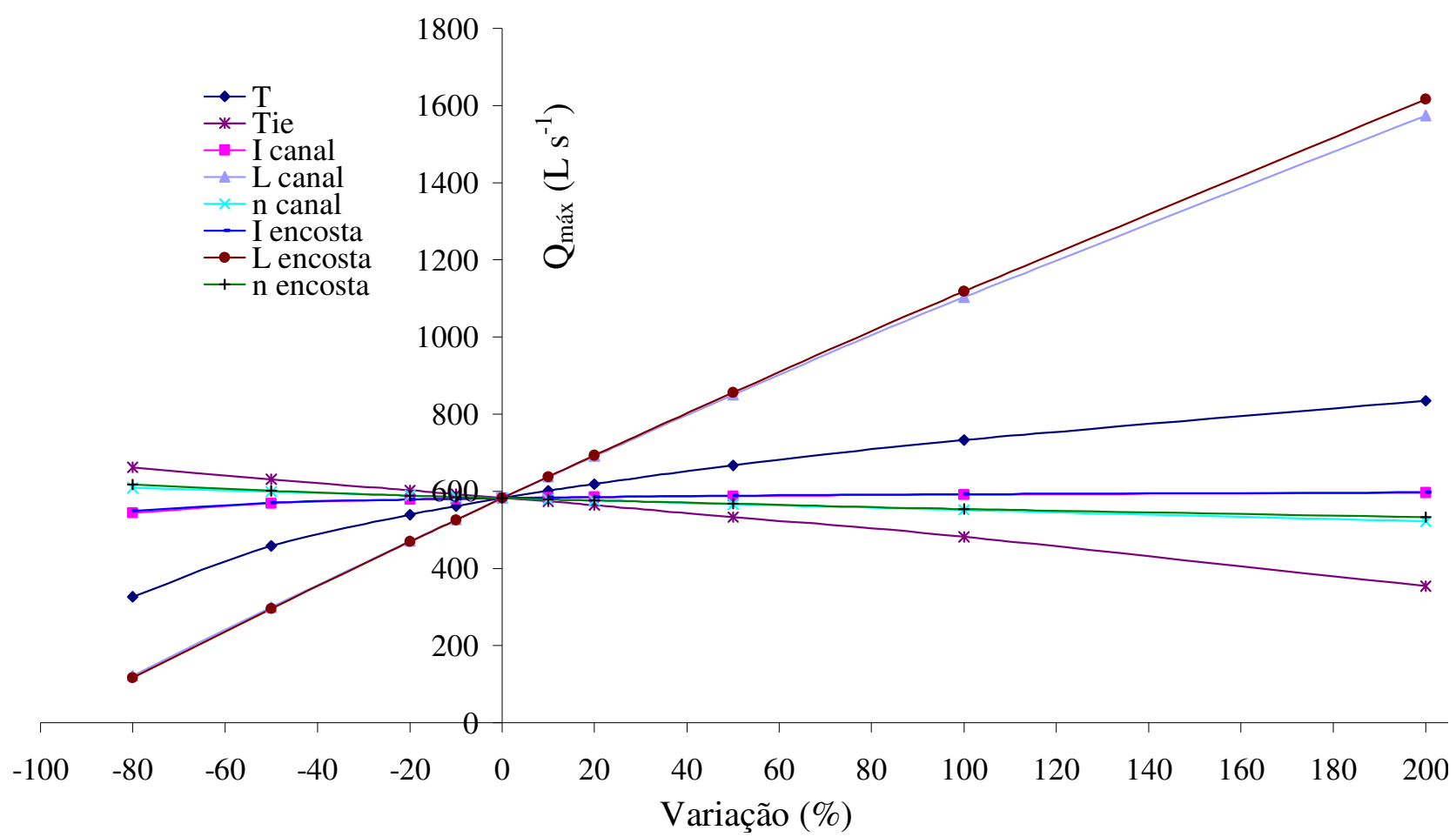

FIGURA 6. Sensibilidade do valor de vazão máxima (Qmáx) calculado pelo modelo às variáveis de entrada.

Na Figura 7, apresenta-se a variação do valor de LES em resposta às mudanças relativas dos valores das variáveis de entrada. Percebe-se que a LES mostrou baixa sensibilidade às declividades, aos comprimentos e aos coeficientes de rugosidade, tanto da encosta quanto do canal.

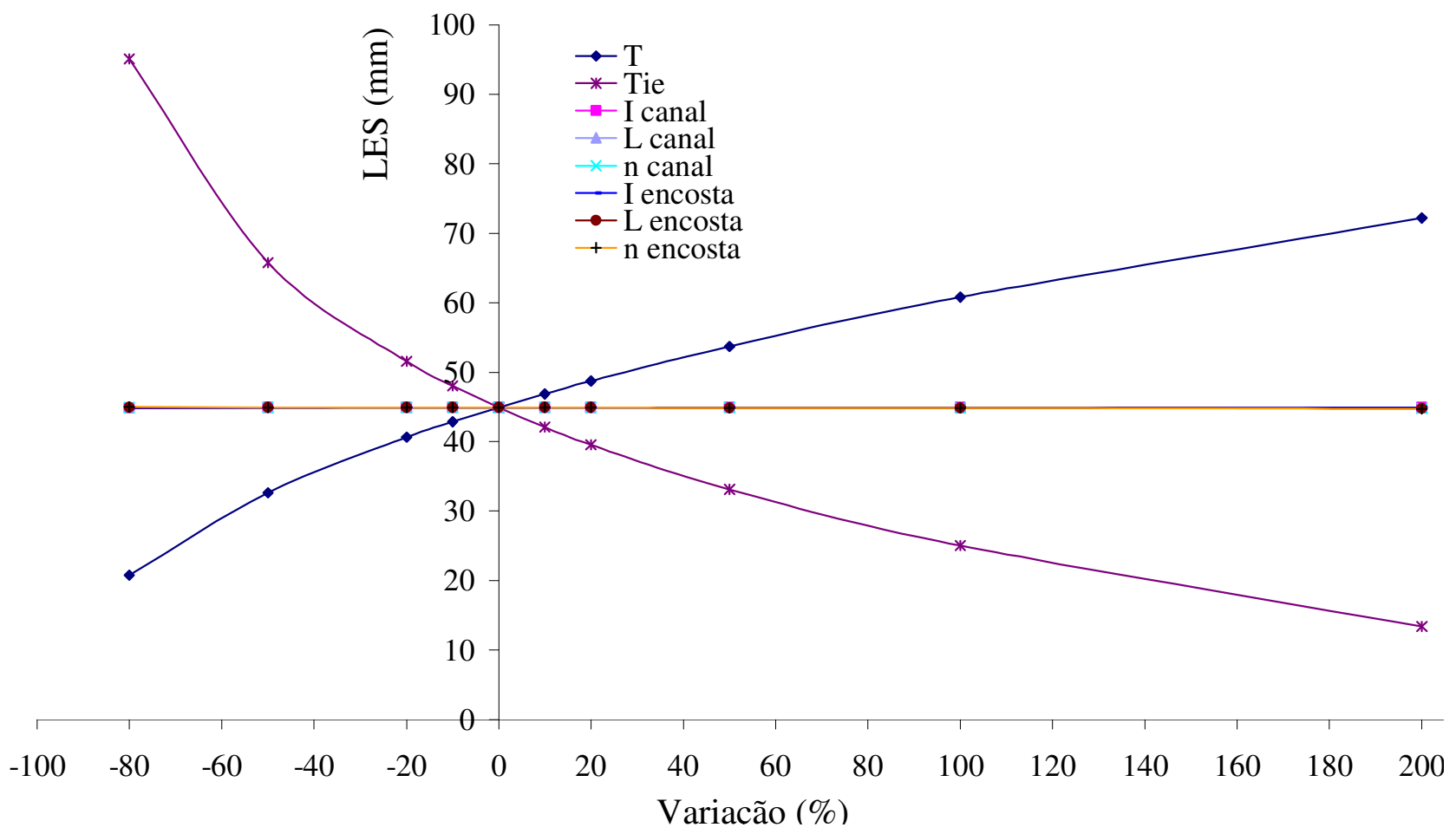

FIGURA 7. Sensibilidade do valor de lâmina de escoamento superficial (LES) calculado pelo modelo às variáveis de entrada. 
Por outro lado, grande sensibilidade está associada às variáveis $\mathrm{T}_{\mathrm{ie}} \mathrm{e} \mathrm{T}$. $\mathrm{O}$ decréscimo dessas variáveis apresentou maior efeito na LES do que seu aumento. Observa-se que a variação da LES tende ser linear com o aumento de $\mathrm{T}$, uma vez que, com o seu crescimento, a intensidade de precipitação estimada tende a ser tão alta que o coeficiente de escoamento se aproxima de um. Percebe-se, ainda, que a LES tende a ser nula com o crescimento da $T_{i e}$, uma vez que esse crescimento faz com que maior parcela da precipitação infiltre no solo, tal que, em uma situação na qual a $\mathrm{T}_{\mathrm{ie}}$ se iguale à intensidade de precipitação, toda a água precipitada seja convertida em infiltração.

Comparando-se os resultados apresentados nas Figuras 6 e 7, é interessante notar que os comprimentos de encosta e canal influenciaram bastante os valores de $\mathrm{Q}_{\text {máx }}$ calculados, não tendo influência sobre a LES. Tal fato ocorre justamente porque a LES representa o volume de água escoada por unidade de área analisada. Variações dos comprimentos de encosta e canal ocasionam variação tanto na área analisada quanto no volume total escoado, o que faz com que os valores da lâmina escoada permaneçam inalterados. Os resultados apresentados tornam de menor importância as variáveis $\mathrm{I}_{\text {canal }}, \mathrm{I}_{\text {encosta }}, \mathrm{n}_{\text {canal }}$, e $\mathrm{n}_{\text {encosta }}$, que são de difícil determinação. Por outro lado, o modelo apresentou alta sensibilidade à $T_{i e}$, que é a variável de mais difícil determinação, exigindo, conseqüentemente, que essa variável seja determinada com o maior rigor possível.

\section{CONCLUSÕES}

O software HIDROGRAMA 2.1, que emprega metodologia baseada em processos físicos, constitui-se em ferramenta útil para a determinação do hidrograma de escoamento superficial, tanto ao longo de encostas como em canais. Além disso, proporciona a quantificação da vazão máxima de escoamento superficial, que é essencial para projetar a seção transversal de canais e do volume escoado superficialmente.

O cálculo da vazão máxima de escoamento superficial pelo modelo apresentou alta sensibilidade ao período de retorno da precipitação, à taxa de infiltração estável da água no solo e aos comprimentos da encosta e do canal.

A lâmina de escoamento superficial apresentou alta sensibilidade ao período de retorno da precipitação e à taxa de infiltração estável da água no solo.

\section{REFERÊNCIAS}

BEASLEY, D. B.; HUGGINS, L. F. Answers: user's manual. Chicago: United States Enviromental Protection Agency, 1981.51 p. Region V.

BERNARDO, S.; SOARES, A.A.; MANTOVANI, E.C. Manual de irrigação. Viçosa: Editora UFV, 2005. $611 \mathrm{p}$.

BONTA, J.V.; RAO, A.R. Estimating peak flows small agricultural watersheds. Journal of Irrigation and Drainage Engineering, Reston, v.118, n.1, p.122-37, 1992.

CHOW, V.T. Open-channel hydraulics. New York: McGraw-Hill, 1986. 680 p.

COMPANHIA DE DESENVOLVIMENTO AGRÍCOLA DE SÃO PAULO - Manual técnico de motomecanização agrícola. São Paulo: CODASP, 1994. 101 p.

GRAY, D.M. Handbook on the principles of hydrology. Nova York: Water Information Center, 1973. $590 \mathrm{p}$.

GOWDA, P.; WARD, A.; WHITE, J.L.; DESMOND, E. The sensitivity of ADAPT model prediction of stream flows to parameters used to define hydrologic response units. Transactions of the ASAE, St. Joseph, v.42, n.2, p.381-9, 1999.

McMILLAN, W.D.; BURGY, R.H. Interception loss from grass. Journal of Geophysical Research, Washington, v.65, n.8, p.2389-94, 1960. 
PINTO, F.A. Chuvas intensas no Estado de Minas Gerais: análises e modelos. 1995. 87 f. Tese (Doutorado em Engenharia Agrícola) - Universidade Federal de Viçosa, Viçosa, 1995.

SCHWAB, G.O.; FREVERT, R.K.; EDMINSTER, T.W.; BARNES, K.K. Soil and water conservation engineering. $2^{\text {nd }}$ ed. New York: John Wiley, 1966. 683 p.

SILVA, J.M.A.; PRUSKI, F.F.; SILVA, D.D.; CECÍLIO, R.A. Metodologia para obtenção do hidrograma de escoamento superficial em encostas e canais. Parte I: Desenvolvimento e avaliação. Engenharia Agrícola, Jaboticabal, v.26, n.3, p.695-703, set./dez.2006.

SIMANTON, J.R.; HAWKINS, R.H.; MOSHENI-SARAVI, M.; RENARD, K.G. Runoff curve number variation with drainage area, Walnut Gulch, Arizona. Transactions of the ASAE, St. Joseph, v.39, n.4, p.1391-4, 1996.

US Department of Agriculture. Soil Conservation Service. National engineering handbook. Washington, 1985. Section 4, Hidrology. 